\title{
Correction to: Projection of seasonal summer precipitation over Indian sub-continent with a high-resolution AGCM based on the RCP scenarios
}

\author{
Sumin Woo ${ }^{1}$ Gyan Prakash Singh ${ }^{2}$ Jai-Ho Oh ${ }^{1}$ (1) $\cdot$ Kyoung-Min Lee ${ }^{3}$
}

Published online: 4 August 2018

(c) Springer-Verlag GmbH Austria, part of Springer Nature 2018

\section{Correction to: Meteorology and Atmospheric Physics https://doi.org/10.1007/s00703-018-0612-7}

The authors would like to include the below text in the acknowledgement section of the Original Publication.

Acknowledgements The authors want to acknowledge the Korea Meteorological Administration research and Development Program under Grant KMI 2018-07910. We also want to acknowledge the Global Science experimental Data hub Center (GSDC) Project, Korea Institute of Science and Technology Information (KISTI) for using computing resources.

The original article can be found online at https://doi.org/10.1007/ s00703-018-0612-7.

Jai-Ho Oh

jhoh@pknu.ac.kr

1 Department of Environmental and Atmospheric Sciences, Pukyong National University, 45, Yongso-ro, Nam-gu, Busan 48513, South Korea

2 Department of Geophysics, Institute of Science, Banaras Hindu University, Varanasi 221005, India

3 CRAY Korea Inc, \#317, 27, Seochojungang-ro, Seocho-Gu, Seoul 06601, South Korea 